\title{
Concepções de diversidade na Base Nacional Comum Curricular - BNCC
}

\author{
ALVES, Eliane Fernandes Gadelha ${ }^{1}$ \\ SALUSTIANO, Dorivaldo Alves ${ }^{2}$
}

\section{RESUMO}

Este artigo apresenta resultados de uma pesquisa documental que teve como objetivo identificar concepções de diversidade no texto da Base Nacional Comum Curricular - BNCC, documento normativo que orientará as escolas na definição e/ou reelaboração de seus currículos. Foram identificadas as concepções universalista, celebratória e crítico-discursiva, com predominância da universalista e da celebratória, evidenciando que a cultura do silenciamento da diversidade se mantém hegemônica nesta política curricular ao enfatizar a uniformidade e a padronização de conhecimentos e indivíduos, secundarizando as diferenças culturais, étnicas, identitárias de vários coletivos de sujeitos (negros, quilombolas, índios, camponeses, mulheres, dentre outros) que reivindicam visibilidade e reconhecimentos em políticas curriculares. Os lugares e significados atribuídos à diversidade no corpus analisado evidenciam que a BNCC se constitui como referencial curricular que prioriza conhecimentos essencializados e universalistas, ao atribuir-lhes destaque em relação aos conhecimentos diversificados e enfatizar um ensino baseado em competências performativas para o mercado de trabalho.

Concepções de Diversidade. Base Nacional Comum Curricular - BNCC. Políticas Curriculares. Sujeitos Sociais.

\section{Diversity Conceptions at the National Common Curricular Base}

\section{ABSTRACT}

This article presents results of a documentary research whose central objective sought to identify the concepts of diversity in the text of the National Common Base Curriculum - BNCC, a normative document that will guide schools in the

\footnotetext{
${ }^{1}$ Mestra em Educação pela Universidade Federal de Campina Grande - UFCG na linha de pesquisa Práticas Educativas e Diversidade. Atualmente trabalha como Supervisora Educacional em escolas públicas no município de Campina Grande/PB. E-mail: elianegadelhaalves@gmail.com. Lattes: http://lattes.cnpq.br/7993699614559372. ORCID: https://orcid.org/0000-0002-9013-8956.

${ }^{2}$ Doutor em Educação Brasileira pela Universidade Federal do Ceará (UFC). Atualmente é Coordenador do Programa de Pós-Graduação em Educação da Unidade Acadêmica de Educação da Universidade Federal de Campina Grande (PPGEd/UFCG). E-mail: dorivaldo.salustiano@gmail.com. Lattes: http://lattes.cnpq.br/7402127637978502.ORCID: https://orcid.org/0000-0002-0956-2451.
}

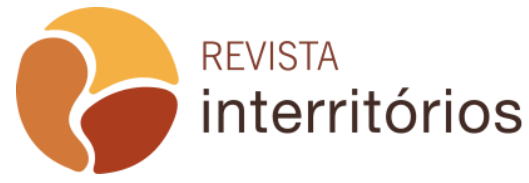


definition and/or reconstruction of their curricula. Universalist, celebratory and critical-discursive concepts were identified. Universalist and celebratory predominated, showing that the culture of silencing diversity remains hegemonic in this curricular policy, which emphasizes the uniformity and standardization of knowledge and individuals, secondary to cultural, ethnic, and identity differences of various collective groups (blacks, quilombolas, natives, peasants, women, landless, among others) who demand visibility and recognition in curricular policies. The places and meanings attributed to diversity in the analyzed corpus show that the BNCC is a curricular reference that prioritizes essentialized and universalist knowledge, by giving it prominence in relation to diversified knowledge, and emphasizing competencebased teaching performative for the labor market.

Diversity concept. National Common Base Curriculum - BNCC. Curriculum

Policies. Social Individuals.

\section{Concepciones de Diversidad en la Base Curricular Común Nacional - Bncc}

\section{RESUMEN}

Este artículo presenta los resultados de una investigación documental que tuvo como objetivo identificar conceptos de diversidad en el texto de la Base Curricular Común Nacional - BNCC, un documento normativo que guiará a las escuelas en la definición y / o reelaboración de sus planes de estudio. Se identificaron concepciones universalistas, celebrativas y discursivas críticas, con predominio de universalistas y celebrativas, que muestran que la cultura de silenciar la diversidad sigue siendo hegemónica en esta política curricular al enfatizar la uniformidad y la estandarización del conocimiento y los individuos, secundaria a las diferencias culturales., identidad étnica, de diversos colectivos de sujetos (negros, quilombolas, indios, campesinos, mujeres, entre otros) que exigen visibilidad y reconocimiento en las políticas curriculares. Los lugares y significados atribuidos a la diversidad en el corpus analizado muestran que BNCC se constituye a sí mismo como una referencia curricular que prioriza el conocimiento esencializado y universalista, dándoles importancia en relación con el conocimiento diversificado y enfatizando la enseñanza basada en habilidades performativas para el mercado laboral.

Concepciones de Diversidad. Currículo Nacional de Base Común - BNCC. Políticas Curriculares. Temas Sociales.

\section{Coscienza de la Diversità Nella Base Curriculare Comune Nazionale - BNCC}

\section{RIASSUNTO}


Questo articolo presenta i risultati di una ricerca documentaria volta a identificare i concetti di diversità nel testo della National Curricular Base BNCC, un documento normativo che guiderà le scuole nella definizione e / o rielaborazione dei loro curricula. Sono state identificate concetti universaliste, celebrative e discorsive-critiche, con una predominanza di universalista e celebrativa, dimostrando che la cultura del silenziamento della diversità rimane egemonica in questa politica curricolare enfatizzando l'uniformità e la standardizzazione della coscienza e degli individui, secondarie alle differenze culturali , etnica, identità di vari collettivi di soggetti (neri, quilombole, indiani, contadini, donne, tra gli altri) che richiedono visibilità e riconoscimento nelle politiche curricolari. I luoghi e i significati attribuiti alla diversità nel corpus analizzato mostrano che il BNCC si costituisce come riferimento curriculare che dà la priorità alla coscienza essenziale e universalistica, dando loro risalto in relazione a coscienze diversificate e sottolineando l'insegnamento basato su abilità performative per il mercato del lavoro.

Coscienza de la diversità. Curriculum nazionale di base comune - BNCC.

Politiche curricular. Materie sociali.

\section{INTRODUÇÃO}

A diversidade tem sido, atualmente, um tema discutido com muita frequência nos âmbitos acadêmico e escolar, nos domínios político, social, midiático, fazendo parte, inclusive, das agendas governamentais nos contextos nacional e internacional. Diversos autores (MOEHLECKE, 2009; ABRAMOWICZ; RODRIGUES; CRUZ, 2011; GOMES, 2012; PIERUCCI, 2013; FERREIRA, 2015; FREIRE, 2013; ARROYO, 2014; BARROS, 2016; CANEN, 2016, SOUSA, 2018; ALVES, 2019) têm se debruçado sobre o estudo dessa temática, demonstrando ser este um campo complexo, instigante e desafiador, que suscita disputas conceituais e posicionamentos políticos, cuja compreensão envolve a discussão de condicionamentos históricos, sociais, políticos e econômicos que orientaram a constituição, organização e posicionamento dos mais diversos grupos sociais ao longo da história.

A diversidade ganhou destaque, também, no campo curricular, uma vez que os coletivos diversos (ARROYO, 2008), ao se reconhecerem sujeitos possuidores de outros conhecimentos, saberes e culturas, questionam propostas curriculares arraigadas em paradigmas tradicionais etnocêntricos.

Esse movimento questionador constituído por sujeitos historicamente invisibilizados e a própria presença destes nas mais diversas instâncias sociais, especialmente na escola, resultou no fomento e implementação de marcos regulatórios que considerassem os coletivos diversos na redefinição de currículos em âmbito nacional, imprimindo, nos documentos legais, suas histórias, culturas, experiências e especificidades. 
Dentre o conjunto de leis que abordam o tema, podemos citar: Parâmetros Curriculares Nacionais - PCN/1997; Lei 10. 639/2003 e, posteriormente a Lei 11.645/2008, que incluiu a temática História e Cultura Afro-Brasileira e Indígena como obrigatórias nos currículos oficiais das escolas; Lei $n^{0}$ 12.796/2013, que altera a Lei $n^{0}$ 9.394, de 20 de dezembro de 1996 e estabelece as diretrizes e bases da educação nacional; Lei no 13.234/2015, que dispõe sobre a identificação, o cadastramento e o atendimento, na educação básica e na educação superior, de alunos com altas habilidades ou superdotação; Lei no 13.632/2018, que dispõe sobre educação e aprendizagem ao longo da vida voltadas à Educação de Jovens e Adultos e educação especial; Lei no 10.436/2002, que dispõe sobre a Língua Brasileira de Sinais - LIBRAS; Lei no 12.711 de 2012 - Lei de Cotas, que dispõe sobre o ingresso de pessoas afrodescendentes, indígenas, mulheres e pessoas com deficiência nas universidades federais e nas instituições federais de ensino técnico de nível médio, como uma política de democratização do acesso ao ensino público. A Base Nacional Comum Curricular - BNCC, documento central nas políticas educacionais atuais, constitui uma política de Estado, de caráter normativo, em implementação em todas as escolas brasileiras, com respaldo na Constituição Federal de 1988, na Lei de Diretrizes e Bases da Educação - LDB 9394/1996, nas Diretrizes Curriculares Nacionais/2013 e no Plano Nacional de Educação/2014.

O presente artigo, resultado de uma pesquisa de mestrado acadêmico em Educação, convida a refletir sobre as concepções de diversidade que permeiam o texto da BNCC, identificadas mediante o emprego da análise de conteúdo (BARDIN, 2016). Neste estudo, buscamos enfrentar o desafio de compreender a diversidade inscrita na BNCC num contexto de desigualdades, realçando a importância dos sujeitos sociais que, na condição de explorados e oprimidos, emergem na história a partir de movimentos e ações coletivas, na luta pela garantia de direitos iguais, sem, contudo, negar suas diferenças. Assim, compartilhamos a perspectiva de Gomes (2012, p. 687), ao compreender a diversidade como

\footnotetext{
construção histórica, social, cultural e política das diferenças, [que] realiza-se em meio às relações de poder $e$ ao crescimento das desigualdades e da crise econômica que se acentuam no contexto nacional e internacional.
}

Reconhecendo a centralidade do currículo escolar para a constituição de práticas educativas em defesa (ou contrárias) a uma educação emancipadora, nos parece oportuno discutir a diversidade a partir de um olhar crítico, levando em consideração as singularidades, potencialidades, vulnerabilidades e desigualdades dos sujeitos. 
Partindo desse pressuposto, buscamos compreender o lugar e os significados que a BNCC, especificamente no texto acerca do ensino fundamental, atribui à diversidade, considerando o contexto social e político no qual o documento foi construído, tendo em vista as várias disputas e tensões dos atores envolvidos no processo de produção desse documento, que, possuindo caráter obrigatório, influenciará a construção dos currículos nas escolas, a produção de livros didáticos, a formação de professores, as políticas de gestão e de avaliação e a própria prática educativa.

Ao considerar o fato de que a BNCC deve nortear a elaboração dos currículos, é necessário compreendê-la como importante ferramenta na produção de visões de mundo e de sociedade que se pretende difundir e/ou consolidar em cada contexto histórico. Portanto, concordamos com Silva (2003, p. 10) ao afirmar, apropriadamente, que

o currículo é o espaço onde se concentram e se desdobram as lutas em torno dos diferentes significados sobre o social e sobre o político. É por meio do currículo, concebido como elemento discursivo da política educacional, que os distintos grupos sociais, especialmente os dominantes, expressam sua visão de mundo, seu projeto social e suas verdades.

Nesse sentido, compreendemos o currículo como um instrumento de poder, imbuído de intencionalidades e interesses, que tem o objetivo de legitimar uma determinada concepção de escola, de conhecimento, de ser humano e de sociedade. Partindo deste pressuposto, questionamos: o tratamento da diversidade na BNCC cria possibilidades de superação das desigualdades de acesso aos conhecimentos dos diversos sujeitos sociais? Ou preserva um currículo que atende às necessidades de formação da classe dominante sob o aparente discurso de igualdade de acesso e garantia dos direitos de aprendizagem de todos?

Desse modo e no intento de compreender o tema em foco, indagamos sobre o lugar e os significados da diversidade na BNCC, anos iniciais do ensino fundamental.

\section{Os efeitos performativos das concepções}

No que se refere às concepções de diversidade presentes no texto da BNCC, compreendemos que elas traduzem orientações, práticas educativas e seleção de conteúdo que podem influenciar na definição do lugar que cada sujeito ocupa no processo educativo. (SILVA 2014; MACEDO, 2015; BALL, 2010; SALUSTIANO, FIGUEIREDO, FERNANDES, 2007). 
Os sujeitos dessa diversidade, mais especificamente os negros, pobres, deficientes, sofrem processos de exclusão e negação muito intensos, que constantemente nos chamam a atenção. Observamos, frequentemente, que as diferenças que caracterizam a singularidade dos sujeitos são invisibilizadas do ponto de vista do currículo, da avaliação, da prática educativa, com base em paradigmas educacionais pautados na homogeneização e padronização do conhecimento, que desconsideram perspectivas alternativas às concepções dominantes. Neste aspecto, Gomes (2007, p. 17) questiona:

Que indagações o trato pedagógico da diversidade traz para o currículo? [...] Como podemos lidar pedagogicamente com a diversidade? [...] Será que existe sensibilidade para a diversidade na educação infantil, especial, na EJA, no ensino fundamental, médio e profissional? [...] qual é o lugar ocupado pela diversidade? Ela figura como tema que transversaliza o currículo? Faz parte do núcleo comum? Ou encontra espaço somente na parte diversificada?

Estes questionamentos suscitam em nós as mesmas inquietações no tocante aos significados da diversidade na BNCC. Frequentemente, temos sido levadas/os a reproduzir um modelo educacional uniforme, homogeneizador, que descaracteriza os diversos sujeitos presentes no âmbito escolar. Exemplo disso são os instrumentos avaliativos padronizados empregados em grande escala, como o Exame Nacional de Ensino Médio (ENEM), o Sistema de Avaliação da Educação Básica (Saeb), as avaliações do atual Programa Mais Alfabetização - PMALFA. São instrumentos avaliativos pautados numa concepção de avaliação de cunho classificatório e quantitativo. Concordamos com Abramowicz, Rodrigues e Cruz (2011, p. 94), quando sustentam que a escola se funda em uma imposição de saber, de uma racionalidade, de uma estética, de um sujeito epistêmico único, legitimado como homogêneo, como parâmetro único de medida, de conhecimento, de aprendizagem e de formação.

Esse paradigma de escola, conforme indicado pelas autoras, é uma realidade que não podemos negar. Os programas e projetos escolares atestam esse fato, uma vez que são pautados em um modelo universalista que tem a finalidade de disseminar um conhecimento único para formar um tipo ideal de sujeito estabelecido como padrão, para uma sociedade que incentiva a competitividade e o ajustamento dos indivíduos ao mercado de trabalho (SAVIANI, 2013; FRIGOTO, 2005; GENTILI, 2002).

Para este paradigma escolar, a/o discente que não acompanha o "padrão" é estigmatizada/o, recebe diversos rótulos e passa a ser visto/a como diferente, pois a diferença, aqui, fica associada a algo negativo, fora da ordem, a um desvio. Em decorrência de suas diferenças, esse/essa aluno/a passa a ser tratado como um "diferente-desigual" (BARROS, 2016) e, para ser

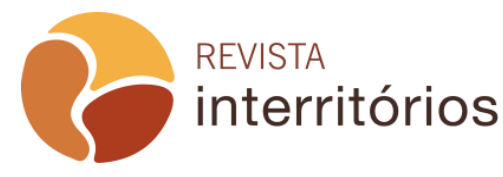


qualificado como "normal", precisa adequar-se aos padrões tidos como legítimos. (ARROYO, 2008; FLEURY, 2006; PATTO, 1990).

Se, por um lado, a escola tem se constituído como agência reprodutora da ordem dominante, a partir, principalmente, de políticas curriculares que desconsideram as diferenças, compartilhamos dos posicionamentos de Freire (2013) e Moreira (2016), que compreendem a escola como um lugar também contra hegemônico, na medida em que o/a professor/a, em sua prática educativa, se coloque como um/a "transgressor/a", que caminhe na direção da emancipação, da formação de sujeitos que não se conformem com normas que visem suprimir suas ideias, calar suas vozes, para subalternizá-los.

Quando propõe a emancipação, Freire (2013), coloca o/a professor/a numa posição ativa, criativa, ao dar um novo significado ao currículo e a sua prática, por meio da valorização dos saberes da experiência. Um saber que Santos (2002) defende como uma via necessária para tornar presentes outras narrativas, novos saberes, contrapondo-se às relações de produção e experiências hegemônicas. Isso não quer dizer que o conhecimento histórico e cientificamente acumulado deva ser desprezado, pois numa sociedade grafocêntrica ele é um elemento importante que possibilita aos indivíduos o acesso aos bens culturais e materiais em sociedades capitalistas marcadas pela competitividade e desigualdade.

Portanto, o que estamos trazendo à evidência é que esses saberes podem ser enriquecidos e ampliados pelas experiências da vida cotidiana de outros sujeitos e culturas, sendo, também, importantes elementos a serem considerados no currículo escolar. Pressuposto que Silva (2018) sustenta no tocante à realidade e cultura dos povos campesinos, cuja mediação pedagógica e o próprio currículo possibilitem dar visibilidade e voz aos saberes e experiências locais. Segundo Silva (2018), trata-se de afirmar a "docência apoiada no compromisso ético do professor com aqueles a quem ensina", condição que permite recuperar "as dimensões epistêmicas, políticas e éticas da ação docente". (SILVA, 2018 p. 91).

Considerando que nossas concepções e nossos referenciais teóricos, éticos, políticos orientam nossa prática educativa e mediação pedagógica (SALUSTIANO; FIGUEIREDO; FERNANDES, 2007) defendemos a necessidade de refletirmos sobre os documentos e diretrizes que são formulados com o objetivo de serem aplicados na escola. A quem interessam? Quais vozes são ouvidas e quais são silenciadas nas práticas que induzem? Que vozes podem se fazer ouvir apesar e por meio deles? Nesta investigação, consideramos a hipótese de que a BNCC, pelas disputas de ideias presentes em sua construção, pode contribuir tanto para o silenciamento dos sujeitos diversos, quanto para um movimento de resistência destes indivíduos pela ressignificação curricular, mediante a materialização do currículo em ação 
(ALBINO, 2018; MOREIRA, 2016; FREIRE, 2013; DORZIAT, 2010; SANTOS, 2002).

\section{Concepções de diversidade na BNCC: universalista, celebratória e crítico-discursiva}

No estudo da diversidade na BNCC destacamos cinco categorias centrais: diversidade cultural, diversidade linguística, inclusão de pessoas com deficiência, currículo comum e diversificado e competências, que expressam três concepções acerca da diversidade: universalista, celebratória e críticodiscursiva. Essas concepções estão fundamentadas em estudos teóricos nos quais diversos autores argumentam em favor da defesa da diversidade como bandeira de luta de movimentos sociais representativos de indivíduos que se consideram excluídos, discriminados social, cultural e economicamente (ARROYO, 2008; BARROS, 2016; FREIRE, 2013; GOMES, 2012) e autores que argumentam em favor da diferença, evidenciando as relações de poder como elemento constituinte da desigualdade (ABRAMOWICZ; RODRIGUES; CRUZ, 2011; DORZIAT, 2010; FLEURY, 2006; PIERUCCI, 2013; SILVA, 2014).

Denominamos de universalista, a concepção que entende a diversidade como expressão de um padrão universal e comum de aprendizagens, destinado a todos os alunos, independentemente de suas diferenças. Toma por base aspectos ou fenômenos que dizem respeito a qualquer sujeito, de modo que as condições que definem determinados indivíduos como diferentes não são definidoras dessa perspectiva. Neste sentido, trata-se de uma concepção substanciada pela noção de igualdade. São exemplos dessa abordagem a referência ao domínio de conhecimentos, saberes, habilidades, práticas culturais, valores etc., considerados universais e essenciais a todas as pessoas.

Esta concepção é compatível com o que Abramowicz, Rodrigues e Cruz (2011, p. 92) definem como uma política cujo caráter universalista busca uma síntese totalizante das diferenças: "as diferenças e as diversidades se configuram como cultura que, por esta via, podem ser trocadas". Tal compreensão perpassa outros documentos oficiais como a Declaração Universal sobre Diversidade Cultural, constituindo-se com uma concepção ancorada nos princípios de uniformidade, de cultura comum, amplamente ratificado pelos organismos internacionais. Rodrigues (2011) explica que essa concepção universalista da diversidade "defende a existência de um princípio comum a todas as culturas e que é este princípio que deve garantir a interação cultural ou a comunicação entre as culturas e os sujeitos." (RODRIGUES, 2011, p. 96). 
Outra perspectiva de compreensão da diversidade, diz respeito à concepção celebratória, problematizada por diversos/as autores/as (DORZIAT, 2010; ABRAMOWICZ; RODRIGUES; CRUZ, 2011; GOMES, 2012; SILVA, 2014). Entendemos por celebratória a concepção de diversidade que tem por base os coletivos de sujeitos considerados como categorias sociais, produtores de culturas específicas. Neste caso, reconhece-se a necessidade de considerar essas culturas como objeto de aprendizagem e como instrumento de reconhecimentos de sujeitos.

Essa perspectiva pressupõe que as diferenças interpessoais podem ser apaziguadas e defendem a tolerância, expressão muito comum nos discursos, prática pedagógica e documentos oficiais, como medida de conciliação de interesses diversos. (SOUSA, 2018; ALVES, 2019). Nesta perspectiva, evidencia-se um discurso valorativo, moral, percebido nos sentidos que se dão as práticas culturais, saberes e linguagens de grupos não hegemônicos, supondo que os interesses desses grupos sociais distintos podem ser conciliados e intercambiados por meio de atitudes de respeito, aceitação e acolhimento das diferenças. Não coloca em discussão as relações de poder.

A ideia de tolerância parece esconder o que de fato existe no tecido social: discriminação, preconceito, estereótipo, exclusão. A adesão à tolerância como princípio orientador da convivência mantém as estruturas hierárquicas dos grupos hegemônicos intactas. A concepção celebratória expressa, ainda, a noção de que coletivos de sujeitos com culturas específicas possam conviver harmoniosamente e participar coletivamente da vida social e das instituições, a exemplo da escola, que deve acolher alunos pertencentes a diferentes etnias, credos religiosos, condições socioeconômicas, identidades sexuais, garantindo uma convivência pacífica e respeitosa por meio do diálogo e da conciliação de conflitos, se beneficiando das diferenças como meio de enriquecimento das relações e formas de saber, numa perspectiva celebratória da diversidade humana.

É possível identificar essa perspectiva nos discursos produzidos pelos organismos internacionais, em vários documentos e textos oficiais, na BNCC, ao propor abordar a diversidade com base no exercício da empatia, diálogo, resolução de conflitos, cooperação, respeito, acolhimento e valorização dos saberes, identidades, culturas e potencialidades de indivíduos e grupos sociais. (BRASIL, 2017).

Ao questionarmos essa concepção, defendemos o entendimento de que, quando a diversidade é assim compreendida, a condição desigual de alguns grupos sociais (resultante de relações de poder que subalternizam indivíduos ou categorias de sujeitos) deixa de ser percebida, visto que a atenção se volta para a variabilidade dos modos e das condições de existência. Dessa forma, produz-se um esvaziamento conceitual que tem servido, tão somente, para ocultar as relações de poder e a hegemonia de

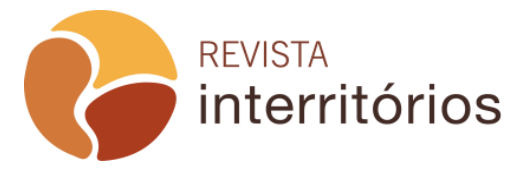


determinados grupos sociais, contribuindo para a solidificação das desigualdades no interior das relações sociais. Neste sentido, Abramowicz e Rodrigues (2013, p. 17) observam que

O uso indiscriminado da diversidade pode restringir-se ao simples elogio às diferenças, pluralidades e diversidades, tornando-se uma armadilha conceitual e uma estratégia política de esvaziamento e/ou apaziguamento das diferenças e das desigualdades.

Tendo em vista essa constatação, faz-se necessário uma compreensão teórica e um posicionamento críticos no tocante a essa abordagem, sobretudo entre os/as educadores/as, como elemento importante para a condução de uma prática educativa que vislumbre os coletivos diversos em suas singularidades e conforme as relações de poder que permeiam suas relações sociais. Tal compreensão é fundamental para o entendimento de políticas curriculares que produzem o apagamento das diferenças, como a BNCC.

Essa perspectiva de diversidade celebratória pode ser facilmente observada nos livros didáticos, nas mídias e nos projetos pedagógicos, propagandeadas em imagens e expressões que enfocam a união de vários grupos sociais, cuja convivência se daria de forma harmônica, sem conflito. Nesse sentido, Abramowicz, Rodrigues e Cruz (2011, p. 85) indicam que "as mãos coloridas dispostas em círculo, os agrupamentos de crianças como representantes de diferentes grupos étnico-raciais e crianças com deficiências unidas sob o título "ser diferente é legal", por exemplo, são representações dessa concepção. Essa abordagem encontra-se subjacente em muitas iniciativas de políticas educacionais e projetos governamentais, projetos escolares, pesquisas acadêmicas, ensaios, artigos, publicidade, entre outros.

Observamos, ainda, uma apropriação dessa perspectiva por parte do movimento neoliberal como forma de expansão dos seus domínios (ABRAMOWICZ; RODRIGUES; CRUZ, 2011). A sociedade capitalista e sua política neoliberal têm se posicionado a partir do viés do reconhecimento, valorização, tolerância da diversidade, propagandeando esse discurso e exaltando a diversidade como um instrumento de maximização do capital, como uma estratégia ideológica, política e econômica que lhes asseguram o fortalecimento do poder hegemônico e expansão mercadológica, aprofundando, ainda mais, a desigualdade.

Essa apropriação e celebração da diversidade pode nos levar a questionar o posicionamento assumido pelos grupos hegemônicos, no sentido de desvelar o que está subentendido nessa celebração. Esse questionamento nos remete ao que Pierucci (2013) chama de "ciladas da diferença", chamando a atenção para uma concreta definição dos termos. A propagação da diversidade, pelos grupos no poder, como se ela abrangesse a todos, pode 
ser uma armadilha, uma cilada para fragmentar as lutas dos grupos sociais diversos, dando a impressão de um Brasil uno, igual, livre de preconceitos. Os grupos hegemônicos, ao se apropriarem das mesmas "armas" dos grupos minoritários, distorcem as intenções e fazem delas seu campo de manipulação discursiva.

O argumento do direito à diferença usada com tanta força pelos sujeitos que a reivindicam, serve, da mesma forma, para os grupos que a desejam distante; é útil, portanto, como elemento discursivo (político), para produzir um "efeito de retorsão", conceito que Taguieff (1986) explica como sendo a posição em que um

contendor se coloca no terreno discursivo e ideológico de seu adversário e o combate com as armas deste, as quais, pelo fato de serem usadas contra ele, deixam de pertencer-lhe pois que agora jogam pelo adversário". (TAGUIEFF Apud PIERUCCI, 2013, p. 52).

É uma estratégia que os grupos dominantes utilizam para tomada e apropriação de um argumento e/ou bandeira de luta, usadas por grupos que defendem a diferença, no entanto, fazendo deles um argumento a favor de seus interesses. Essa perspectiva é destacada por Abramowicz, Rodrigues e Cruz (2011, p. 93), ao afirmar que: "o neoliberalismo se aproveita da palavra de ordem pela diferença que significa a possibilidade de ampliação do mercado".

Uma terceira perspectiva, que se contrapõe à universalista e à celebratória, é a crítico-discursiva. Denominamos crítico-discursiva a abordagem da diversidade que coloca em evidência o desvelamento das estruturas de poder, o enfrentamento às atitudes de discriminação e estereótipos que os coletivos diversos sofrem na sociedade, bem como reivindica currículos e práticas educativas voltadas às diferenças (ABRAMOWICZ; RODRIGUES; CRUZ, 2011; ARROYO, 2014; FREIRE, 2013; GOMES, 2007; DORZIART, 2010; CANEN; XAVIER 2011). Considera os aspectos socioeconômicos, políticos e relações de poder como constituintes da diversidade de sujeitos e enfatiza um discurso pautado na afirmação das diferenças como bandeira de luta dos sujeitos e grupos identitários que afirmam e disputam o lugar das diferenças nos mais diversos contextos: político, social, educacional, ocupacional, econômico, dentre outros, na busca por direitos, visibilidade social e política.

Essa perspectiva coloca no centro de debates as contradições, exploração, desigualdades, relação de poder e resistências envolvidas na luta dos diversos povos, especialmente os indígenas e africanos. Pressupõe uma abordagem da diversidade que coloca em discussão o desvelamento das estruturas de poder, o enfrentamento de atitudes de discriminação e 
estereótipos, bem como põe em evidência práticas educativas voltadas às diferenças, afirmando-as no contexto social e político.

Encontramos, nessa perspectiva, a luta dos coletivos diversos através dos movimentos sociais, que, ao afirmar suas diferenças, denunciam as desigualdades, a opressão, discriminação e reivindicam seu lugar na estrutura social e política.

\section{Metodologia}

Esta pesquisa se caracteriza como um estudo documental, de caráter qualitativo, em que a categoria diversidade foi analisada como base no referencial teórico-metodológico da análise de conteúdo (BARDIN, 2016), buscando revelar o lugar e os significados que lhe são atribuídos no texto da BNCC. A intenção de uma análise documental consiste em realizar inferências sobre o que está registrado no documento, ou seja, os valores, interesses, intenções, concepções e significados do que é dito e não dito. (LUDKE; ANDRÉ, 2017; MINAYO, 2008).

A escolha da BNCC como documento fonte de análise justifica-se pela centralidade que ocupa como política de Estado nas propostas curriculares em nível nacional, e expressa em relatórios e documentos do Ministério da Educação e de diversos grupos, instituições e demais autores, que assumem tanto posicionamentos antagônicos como favoráveis ao documento.

A análise de conteúdo possibilita verificarmos quais concepções, valores, interesses e intenções estão delineadas na BNCC no tocante à abordagem da diversidade. Para tanto, orientamos a sistematização e análise textual conforme as três fases propostas por Bardin (2016) para a realização de uma análise de conteúdo, a saber: a pré-análise, exploração do material e tratamento dos resultados. Desse modo, após procedermos uma leitura preliminar e aprofundada do documento, realizamos um mapeamento dos aspectos centrais relacionados à diversidade, a partir do capítulo introdutório, que traz uma abordagem geral dos pressupostos discutidos no documento, assim como das seções que tratam das competências gerais e específicas, das habilidades e dos objetos de aprendizagens das diversas áreas de conhecimento.

Com base nesse mapeamento, construímos um quadro de categorias analíticas designadas por palavras ou expressões em torno das quais reunimos unidades de registros (dados textuais) que possuíam significados comuns. Dessa forma, estabelecemos as categorias diversidade cultural, diversidade linguística, inclusão de pessoas com deficiência, currículo comum e diversificado, competências. 
Demonstramos, a seguir, com base em exemplos extraídos de cada categoria, como as concepções de diversidade delineadas acima se materializam no texto da BNCC. Os dados apresentados neste artigo representam, portanto, parte do material produzido na pesquisa de Alves (2019), para a qual remetemos o leitor interessado em aprofundar este estudo.

\section{Resultados e Discussões}

A BNCC traz orientação para um currículo voltado para o reconhecimento da diversidade cultural, fazendo referência à diversidade que expressa aspectos identitários de variados grupos sociais. Podemos observar esses aspectos nas competências gerais e em diversas áreas do conhecimento: história, geografia, religião, artes, dentre outros.

No ensino de geografia, na unidade temática "o sujeito e seu lugar no mundo" e no objeto de conhecimento "território e diversidade cultural", a habilidade 1 , indicada para o $4^{\circ}$ ano do ensino fundamental, propõe que os alunos aprendam a

Selecionar, em seus lugares de vivência e em suas histórias familiares e/ou da comunidade, elementos de distintas culturas (indígenas, afro-brasileiras, de outras regiões do país, latino-americanas, europeias, asiáticas etc.) valorizando o que é próprio em cada uma delas e sua contribuição para a formação da cultura local, regional e brasileira. (BRASIL, 2017, p. 375).

Podemos reconhecer, nesta habilidade, um exemplo de uma proposta didático-pedagógica preocupada em selecionar os elementos de culturas distintas, considerando as histórias de vida, familiar e comunitária como expressão do valor de cada uma delas e sua contribuição para a formação do povo brasileiro. Aspecto que podemos constatar, também, na habilidade 6 , do $4^{\circ}$ ano, voltada para o propósito de

identificar e descrever territórios étnico-culturais existentes no Brasil, tais como terras indígenas e de comunidades remanescentes de quilombos, reconhecendo a legitimidade da demarcação desses territórios. (BRASIL, 2017, p. 375).

Nas duas habilidades apresentadas nos exemplos acima, o foco de atenção são atributos identitários, elementos de identificação e descrição dos povos e territórios étnicos-culturais, cuja finalidade reside no reconhecimento, valorização e contribuição desses grupos coletivos. Embora indiquem que se trata de coletivos constituídos por diferentes etnias e territórios, com histórias, valores, culturas específicas, não mencionam as contradições, explorações,

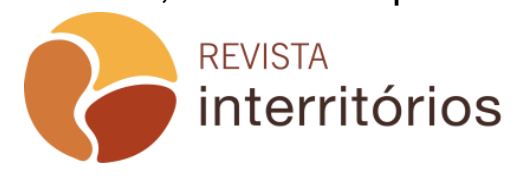


relações de poder e resistências envolvidas na luta dos diversos povos, especialmente os indígenas e africanos.

O enfoque dado às habilidades citadas expressa uma concepção celebratória da diversidade desses grupos e suas culturas no currículo, na medida que propõe reunir e compartilhar seus traços identitários em coletivo acolhedor das contribuições de cada coletivo de sujeitos, sejam europeus, latino-americanos, asiáticos, afro-brasileiros, indígenas, quilombolas. $\mathrm{O}$ reconhecimento desses coletivos diversos é indicado, apenas, em termos de evidências de uma narrativa histórica, sem trazer, também, os elementos contraditórios da sua existência e das lutas desses povos. Ao tratar da diversidade cultural e dos coletivos diversos, a BNCC o faz, frequentemente, usando expressões valorativas, benevolentes, fazendo crer que os interesses de grupos sociais distintos podem ser conciliados por meio de atitudes de respeito, aceitação, tolerância, acolhimento das diferenças.

É importante destacar que, embora tenhamos nessas duas habilidades uma perspectiva celebratória, precisamos considerar que a presença desses temas no currículo será discutida por professores/as que assumem diferentes concepções de diversidade, de modo que, dependendo do significado que o/a professor/a atribui à diversidade, os encaminhamentos didático-pedagógicos podem tomar contornos diferentes, ou seja, continuar nessa perspectiva celebratória, ou ser um elemento possibilitador de uma discussão crítica, problematizadora.

A análise do documento possibilitou identificar propostas de atividades e estratégias metodológicas relacionadas à diversidade linguística, conforme exemplificamos a seguir. A competência específica 4, de Língua Portuguesa, propõe

Compreender o fenômeno da variação linguística, demonstrando atitude respeitosa diante das variedades linguísticas e rejeitando preconceitos linguísticos. (BRASIL, 2017, p. 85).

Percebemos a intencionalidade dada ao trabalho com a diversidade linguística na escola, destacando que existem preconceitos linguísticos, de modo que a orientação pedagógica está voltada ao respeito para com as variedades linguísticas e o desafio de rejeitar atitudes preconceituosas no tocante a este fenômeno. Nesse sentido, em se tratando de Língua Portuguesa, faz parte do conjunto de princípios e pressupostos levar os alunos a

conhecer e valorizar as realidades nacionais e internacionais da diversidade linguística e analisar diferentes situações e 
atitudes humanas implicadas nos usos linguísticos, como o preconceito linguístico. (BRASIL, 2017, p. 68).

Ainda no componente curricular Língua Portuguesa, no eixo de "Análise Linguística/Semiótica", a BNCC traz como conhecimentos linguísticos relacionados à Variação Linguística:

Conhecer algumas das variedades linguísticas do português do Brasil e suas diferenças fonológicas, prosódicas, lexicais e sintáticas, avaliando seus efeitos semânticos. (BRASIL, 2017, p. 81).

Discutir, no fenômeno da variação linguística, variedades prestigiadas e estigmatizadas e o preconceito linguístico que as cerca, questionando suas bases de maneira crítica. (BRASIL, 2017, p. 81).

Nesse contexto, constatamos que a discussão acerca da variação linguística, proposta na competência específica e no componente curricular de Língua Portuguesa, expressam uma concepção crítico-discursiva sobre a diversidade, na medida em que discute a necessidade de questionar estigmas e preconceitos no tocante ao uso dessas línguas e a respeito de seus falantes.

Aqui, mais uma vez, põe-se em discussão o padrão, a norma que coloca em evidência uma única forma de falar o português, a exemplos dos livros didáticos, do currículo e da própria ação educativa, quando sua prioridade reside no estudo da estrutura da língua em detrimento de suas funções comunicativas. Assim, em muitos casos, o papel da escola tem sido desenvolver no educando competências linguísticas socialmente aceitas, sem levar em consideração o contexto social diverso em que se encontra. Em decorrência disso, se estigmatiza os sujeitos que não se expressam conforme a norma culta quanto ao uso da língua portuguesa (BAGNO, 2002). Esse viés não considera que a língua nos constitui, que tem significados social e culturalmente muito importantes e bastante peculiares para os diferentes grupos de falantes que dela se utilizam, conforme a variabilidade de contextos socioculturais.

O enfoque crítico acerca da diversidade linguística expresso, majoritariamente, pelo componente curricular de Língua Portuguesa e suas competências específicas presentes na BNCC, ainda que não sejam predominantes no conjunto do texto, é um aspecto positivo, de suma relevância. Contudo, contraditoriamente, no contexto social e, infelizmente, no cotidiano da escola, muitos grupos sociais são estigmatizados pela forma como falam. A predominância da língua padrão como aquela que tem primazia nos diversos contextos formais, quando não evidenciadas a existência e legitimidade de outras formas de falar, de expressar sua cultura, sua 
identidade social, representa uma forma de exclusão dos falantes de variantes linguísticas.

Nesse sentido, os aspectos apontados em Língua Portuguesa e sua respectiva competência pela BNCC ensejam um tratamento crítico dessas questões pelos/as professores/as que estejam atentos/as às diversas formas de abordagem da diversidade. Por isso, consideramos importante discutir as concepções de diversidade presentes na BNCC, para que os/as professores/as possam se beneficiar desse esclarecimento, conforme suas posições políticas, suas filiações identitárias, seus lugares de inserção social.

$\mathrm{Na}$ categoria Inclusão de Pessoas com Deficiência, reunimos ocorrências de dados da BNCC presentes no capítulo introdutório, nas competências e objetos de conhecimento, que indicam a necessidade de reconhecimento de suas diferenças como um fator de inclusão no sistema de ensino regular, assegurando a todos os sujeitos o direito à educação, conforme preconizado na Constituição Federal, em seu Art. 205.

A BNCC, como podemos constatar, apresenta orientação curricular na perspectiva de uma educação inclusiva, destacando, na Competência Geral 4 da Educação Básica, a inclusão da Língua Brasileira de Sinais - LIBRAS no contexto escolar, constante do capítulo introdutório, indicando a necessidade de "utilizar diferentes linguagens - verbal (oral ou visual-motora, como Libras") (BRASIL, 2017, p. 9).

Sabemos que, na prática, há uma lacuna muito grande para que, de fato, esses direitos se efetivem. A inclusão constitui, ainda, um desafio para nossas instituições. Muitas vezes, não se sabe o que fazer, pedagogicamente, com pessoas com deficiência. Há uma grande dificuldade em transpor os paradigmas que embasam a tradição educacional, desde a formação docente no ensino superior, pautada em um currículo homogêneo e que perpassa as nossas escolas e reverberam em nossa prática pedagógica. Mantoan (2003, p. 29) problematiza, de forma adequada, a resistência da escola à inclusão, afirmando que as instituições escolares

refletem a sua incapacidade de atuar diante da complexidade, da diversidade, da variedade, do que é real nos seres e nos grupos humanos. Os alunos não são virtuais, objetos categorizáveis - eles existem de fato, são pessoas que provêm de contextos culturais os mais variados, representam diferentes segmentos sociais, produzem e ampliam conhecimentos e têm desejos, aspirações, valores, sentimentos e costumes com os quais se identificam.

É mediante a existência dos diversos sujeitos com suas idiossincrasias que não se justifica a permanência de uma educação escolar pautada na uniformização curricular, com predominância de conhecimentos, conteúdos, 
disciplinas, metodologias e avaliações cujas finalidades estão em formar o/a aluno/a ideal, produtivo, adequado às exigências mercantis. Nessa trama, categorias são estabelecidas, classificando o/a aluno/a em normal/deficiente, bom(boa)/ruim, apto(a)/inapto(a), branco(a)/negro(a), rico(a)/pobre, inteligente/atrasado(a), dentre outras. Tal categorização contribui para 0 fortalecimento de práticas excludentes e discriminatórias.

Nesta categoria, portanto, identificamos o predomínio da concepção celebratória de diversidade, uma vez que, embora exista o reconhecimento dos sujeitos diversos, sua identidade, cultura, saberes são considerados tendo em vista a necessidade de considerar essas culturas como objeto de aprendizagem; o tratamento dado a estes sujeitos está voltado, frequentemente, ao desenvolvimento de valores morais no trato com a diferença. Nesse contexto, é necessário que a retórica do respeito esteja acompanhada de uma reflexão crítica no tocante às diferenças no sentido de desconstruir visão estereotipada dos sujeitos que apresentam alguma deficiência, seja ela física, motora, intelectual dentre outras, uma vez que essa visão pode ser um elemento complicador do processo de mediação pedagógica, resultante de concepções reducionistas e infundadas sobre os sujeitos da educação especial. Nesse sentido, o trato pedagógico com as crianças especiais pautado apenas em gestos e atitudes amistosas, desprovido de uma visão crítica, reforça o preconceito e a discriminação, aprofundando as desigualdades.

A BNCC divide o currículo escolar em duas partes, "comum e diversificada", nos quais as aprendizagens são distribuídas. A parte comum corresponde aos conhecimentos básicos, ao currículo mínimo obrigatório, definidos em lei, e que devem ser ensinados em todo o país. Esses conhecimentos básicos serão considerados universais, unificados para todas as escolas do Brasil. A parte diversificada se constitui dos saberes e práticas sociais locais e particulares, conforme a especificidade regional, cultural e os aspectos próprios da realidade escolar e das crianças. Em consequência desta hierarquização, as temáticas que envolvem a diversidade ficam à margem do currículo e podem ser consideradas, no contexto da prática, um saber menos "importante" ou de menor "validade", o "qual os/as educadores/as sabem que, hierarquicamente, por mais que possamos negar, ocupa um lugar menor do que o núcleo comum" (GOMES, 2002, p. 2).

Podemos observar essa divisão curricular no capítulo introdutório do documento ao afirmar que a BNCC é um

documento de caráter normativo que define o conjunto orgânico e progressivo de aprendizagens essenciais que todos os alunos devem desenvolver ao longo das etapas e modalidades da Educação Básica. (BRASIL, 2017, p. 8, grifo nosso). 
Pelo exposto, podemos constatar que a BNCC determina os conhecimentos essenciais a que os/as estudantes de todo o Brasil precisam ter acesso e se apropriar, desde a educação infantil até o ensino médio. Eles buscam fixar "um patamar comum de aprendizagens a todos os estudantes" (2017, p. 8), trazendo a ideia de uma abordagem homogênea e uniforme no processo de ensino e aprendizagem. Estabelece, também, uma hierarquia entre conteúdos considerados "essenciais", que serão contemplados na parte comum do currículo, em detrimento dos conhecimentos que envolvem abordagens da diversidade. A definição da BNCC do que é nacional/comum dentro de uma ótica universalista, como conhecimento que deve ter primazia em relação à diversidade dos saberes e práticas sociais, quantificando, inclusive, os conteúdos curriculares em 60\% (parte comum) e até $40 \%$ (parte diversificada), privilegia os conhecimentos essenciais, que estão na parte comum e se constitui de uma obrigatoriedade no processo de ensino. Desse modo, contribui para o silenciamento das diversas culturas e saberes dos sujeitos sociais que têm acesso à escola, deixando a cargo dos entes federados e das secretarias de educação de cada estado e município a inclusão dos conteúdos específicos.

Nesse sentido, a Anped (2015, p. 14) problematiza o "poder hegemônico do comum, do nacional, do universal", que será reforçado por "políticas de avaliações, distribuição de materiais didáticos e formação de professores", fato que "tenderá a promover hierarquização entre conhecimentos, dando legitimidade àquilo que é de todos fazendo silenciar e desaparecer o que é local e sugerido como parte diversificada."

Pelo exposto a BNCC demonstra e confere ao currículo caráter universalista no que diz respeito àquilo que se deve ensinar e aprender na Educação Básica, assim como à capacidade de os/as estudantes colocarem em prática o conjunto de conhecimentos, saberes, valores, de modo que opera em função de uma homogeneidade coletiva.

Assim, a concepção universalista é predominante nesta categoria, uma vez que envolve todos os sujeitos, independentemente de suas subjetividades, dentro de um padrão de conhecimento universal, comum a todos.

Ao longo dos níveis de ensino, a Base estabelece dez competências, definidas como

a mobilização de conhecimentos (conceitos e procedimentos), habilidades (práticas, cognitivas e socioemocionais), atitudes e valores para resolver demandas complexas da vida cotidiana, do pleno exercício da cidadania e do mundo do trabalho. (BRASIL, 2017 p. 8). 
A BNCC define os objetos de conhecimentos, presentes em todas as áreas do conhecimento, determinando sua apropriação e acesso na Educação Básica por todos/as os/as alunos/as que estão articulados com as competências e habilidades a serem desenvolvidas.

As competências presentes na BNCC precisam ser desenvolvidas por todos/as os/as alunos/as, a fim de que sua aprendizagem seja, de fato, possível. Assim, a BNCC:

indica que as decisões pedagógicas devem estar orientadas para o desenvolvimento de competências. Por meio da indicação clara do que os alunos devem "saber" (considerando a constituição de conhecimento, habilidades, atitudes e valores), e, sobretudo, do que devem "saber fazer" (considerando a mobilização desses conhecimentos, habilidades e valores para resolver demandas complexas da vida cotidiana, do pleno exercício da cidadania e do mundo do trabalho), a explicitação das competências oferece referências para o fortalecimento de ações que assegurem as aprendizagens essenciais definidas na BNCC. (BRASIL, 2017, p. 13).

Compreendemos, portanto, que esta categoria retrata uma concepção universalista, perspectiva associada à ideia de currículo comum, constituído por aprendizagens essenciais a todos/as os/as alunos/as e à noção de competências e habilidades.

\section{Considerações Finais}

Considerando o ambiente político que estamos vivenciando atualmente, marcado por autoritarismos, aprofundamento das desigualdades e negação dos direitos dos coletivos diversos, consideramos que as concepções de diversidade que delineamos neste trabalho podem se constituir um instrumento de luta para os/as educadores/as engajados/as em propostas curriculares voltadas aos interesses dos coletivos de sujeitos que se encontram em condições de desigualdade e exclusão social.

Os resultados da nossa pesquisa demonstram que a BNCC expressa a forte influência dos organismos internacionais na política educacional do Brasil. Percebemos que tais organismos exercem um grande poder na formulação dos documentos oficiais, que são normativos para a construção dos currículos das escolas brasileiras, de modo que os pressupostos defendidos por esses organismos reverberam em nossas políticas públicas educacionais. 
Apesar desse gerenciamento externo e das forças privatistas, detentores de maiores poderes políticos e econômicos, entendemos que o/a professor/a tem a possibilidade de forjar o currículo mediante sua ação educativa ao engajar-se, politicamente, no sentido de dar vez e voz aos saberes e culturas dos coletivos diversos, historicamente negados no processo curricular, negação que se deu/dá não apenas numa perspectiva política, econômica, mas, também, cultural.

As concepções universalista, celebratória e concepção críticodiscursiva discutidas neste trabalho indicam diferentes modos de compreender a diversidade. Os dados analisados indicam a predominância das concepções celebratória e universalista de diversidade em inúmeros contextos sociais e em políticas curriculares, especialmente no texto da BNCC. Apesar do caráter normativo que a informa, defendemos que a BNCC seja pensada e discutida entre os educadores numa perspectiva crítica, no sentido de não ser vista como um instrumento absoluto, tendo em vista que o contexto da prática é muito dinâmico em decorrência da existência dos diversos sujeitos que, diariamente, trazem vida ao currículo, construindo e reconstruindo conhecimentos a partir das relações estabelecidas com outros sujeitos, que trazem consigo novos saberes e vivências.

Consideramos que este artigo pode contribuir para um maior aprofundamento da discussão que envolve a diversidade, rompendo com o olhar meramente folclórico e ampliando para um olhar mais crítico, problematizador das questões que envolvem relações de poder, desigualdade, opressão, exploração pelos quais os coletivos diversos sofreram/sofrem ao longo da história.

A sistematização de modos de compreensão e posicionamento político acerca do tema, a explicitação de algumas das complexidades e contradições que o cercam, a indicação de como se faz presente no cotidiano das salas de aula, das políticas curriculares e da ação política de organizações sociais, de governos e organismos internacionais contribuem para maior clareza da prática educativa e da participação política.

\section{REFERÊNCIAS}

ABRAMOWICZ, Anete. et.al. A diferença e a diversidade na educação.

Contemporânea. Revista de Sociologia da UFSCar, São Carlos, Departamento de Pós-Graduação em Sociologia da UFSCar, 2011, n. 2. p. 85-97. Disponível em: http://www.contemporanea.ufscar.br/index.php/contemporânea/article/download/38 /20. Acesso em: 19 nov. 2016.

ALBINO, Ângela Cristina Alves. Currículo e autonomia docente: enunciações políticas. Curitiba, ed.: Appris, 2018. 
ALVES, Eliane Fernandes Gadelha. Concepções de diversidade na Base Nacional Comum Curricular - anos iniciais do ensino fundamental/Dissertação (Mestrado em Educação) - Centro de Humanidades. Universidade Federal de Campina Grande. Campina Grande, 2019.

ARROYO, Miguel G. Os coletivos diversos repolitizam a formação. In: DINIZPEREIRA, Júlio Emíllio; LEÃO, Geraldo (Orgs.). Quando a diversidade interroga a formação docente. Belo Horizonte: Autêntica, 2008. p. 11-36.

ARROYO, Miguel Gonzalez. Outros Sujeitos, Outras Pedagogias. 2. ed. Petrópolis, RJ: Vozes, 2014.

ANPED. A Associação Nacional de Pós-Graduação e Pesquisa em Educação (ANPED) e a Base Nacional Comum Curricular (BNCC), 2015.

BAGNO. Marcos. Preconceito linguístico: o que é, como se faz. 15 ed. São Paulo: Loyola, 2002.

BALL. Stephen J. Performatividades e Fabricações na Economia Educacional: rumo a uma sociedade performativa. In.: Performance, Performatividade e Educação. Universidade Federal do Rio Grande do Sul - UFRGS. Rev. Educação e Realidade, v. 35, n. 02, maio/agosto, 2010.

BARDIN. Laurence. Análise de conteúdo. Edições 70. São Paulo: 2016.

BARROS, José D'Assunção. Igualdade e diferença: construções históricas e imaginárias em torno da desigualdade humana. Petrópolis, RJ: vozes, 2016.

BRASIL. Constituição da República Federativa do Brasil de 1988. Disponível em: www.planalto.gov.br/ccivil. Acesso em: 19 nov. 2016.

BRASIL. Lei no 9.394, de 20 de dezembro de 1996. Diário Oficial da União, Brasília, DF, 1996. Disponível em:

http://www.planalto.gov.br/ccivil_03/Leis/L9394.htm. Acesso em: 19 nov. 2016.

BRASIL. Ministério da Educação. Parâmetros curriculares nacionais. 3 ed. Brasília: MEC/ SEF, 1997.

BRASIL. Lei no 10.436 de 24 de abril de 2002. Dispõe sobre a Língua Brasileira de Sinais - Libras e dá outras providências. Disponível em:

http://www.planalto.gov.br/ccivil_03/leis/2002/l10436.htm. Acesso em: 19 nov. 2016.

BRASIL. Lei 10.639 de 9 de janeiro de 2003. Altera a Lei no 9.394, de 20 de dezembro de 1996, que estabelece as diretrizes e bases da educação nacional. Brasília: [s.n.], 2003.

BRASIL. Lei 11.645 de 10 de março de 2008. Disponível em: www.planalto.gov.br/ccivil_03/_ato2007-2010/2008/lei/l11645.htm. Acesso em: 19 nov. 2016.

BRASIL. Lei $\mathbf{n}^{\circ}$ 12.711, de 29 de agosto de 2012. Dispõe sobre o ingresso nas universidades federais e nas instituições federais de ensino técnico de nível médio e dá outras providências. Disponível em: 
http://www.planalto.gov.br/ccivil_03/_Ato2011-2014/2012/Lei/L12711.htm. Acesso em: 16 out. 2016.

BRASIL. Diretrizes Curriculares Nacionais Gerais da Educação Básica/ Ministério da Educação. Secretária de Educação Básica. Diretoria de Currículos e Educação Integral. - Brasília: MEC, SEB, DICEI, 2013. Disponível em:

http://portal.mec.gov.br/docman/julho-2013-pdf/13677-diretrizes-educacao-basica2013-pdf/file. Acesso em: 14 nov. 2017.

BRASIL. Lei no 12.796, de 04 de abril de 2013. Estabelece as diretrizes e bases da educação nacional, para dispor sobre a formação dos profissionais da educação e dar outras providências. Disponível em:

http://www.planalto.gov.br/ccivil_03/_Ato2011-2014/2013/Lei/L12796.htm\#art2.

Acesso em: 05 abr. 2020.

BRASIL. Lei no 13.005, de 25 de junho de 2014. Aprova o Plano Nacional de Educação - PNE e dá outras providências. Diário Oficial da União, Brasília, DF., 26 jun. 2014. Disponível em: https://www.planalto.gov.br/ccivil_03/_ato20112014/2014/lei/l13005.htm. Acesso em: 14 abr. 2020.

BRASIL. Lei no 13.234, de 29 de dezembro de 2015. Dispõe sobre a identificação, o cadastramento e o atendimento, na educação básica e na educação superior, de alunos com altas habilidades ou superdotação. Disponível em:

http://www.planalto.gov.br/ccivil_03/_ato2015-2018/2015/lei/l13234.htm. Acesso em: 12 abr. 2020.

BRASIL. Base Nacional Comum Curricular. Disponível em:

http://basenacionalcomum.mec.gov.br./site/base/. Acesso em: 10 jul. 2017.

BRASIL, Lei no 13.632, de 06 de março de 2018. Dispõe sobre educação e aprendizagem ao longo da vida. Disponível em:

http://www2.camara.leg.br/legin/fed/lei/2018/lei-13632-6-marco-2018-786231publicacaooriginal-154957-pl.html. Acesso em: 05 jun. 2020.

CANEN, Ana; XAVIER, Giseli Pereli de Moura. Formação continuada de professores para a diversidade cultural: ênfases, silêncios e perspectivas. Revista Brasileira de Educação, v. 16 n. 48 set.- dez. 2011.

DORZIAT, Ana. Implicações da globalização na política de inclusão escolar: reflexões para além de inclusão enquanto inserção física. Revista Temas em Educação, João Pessoa, v. 18/19, n. 1/2, p. 88-113, jan.-dez. 2009/2010.

DORZIAT, Ana; LIMA, Niedja Maria Ferreira de. Formação docente para educar na diversidade: concepções subjacentes nos documentos oficiais e na prática explicitada. Ensaio: aval. pol. públ. Educ., Rio de Janeiro, v. 23, n. 87, p. 437-460, abr./jun. 2015.

FERREIRA. Windiz Brazão. O conceito de diversidade no BNCC: relações de poder e interesses ocultos. Retratos da escola, v. 9, n. 17, julho/dez. 2015. Brasília: CNTE, 2007.

FLEURI, Reinaldo. Políticas da diferença: para além dos estereótipos na prática educacional. Campinas: Revista Educação \& Sociedade, v. 27, n. 95, p. 495-520,

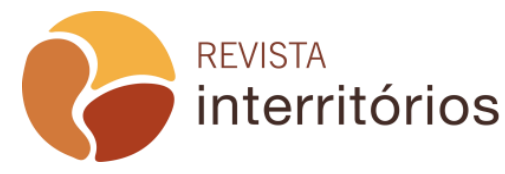


mai-ago. 2006. Disponível em:

http://www.scielo.br/pdf/\%0D/es/v27n95/a09v2795.pdf. Acesso em: 18 ago. 2018.

FREIRE, Paulo. Pedagogia do oprimido. Rio de Janeiro: Paz e Terra, 2013.

FRIGOTO, Gaudêncio. Escola pública brasileira na atualidade lições da história. In: LOMBARDI, José Claudinei; SAVIANI, Dermeval; NASCIMENTO, Maria Isabel Moura (Orgs.) A escola pública no Brasil: história e historiografia. Campinas, SP Autores Associados HISTEDBR, 2005.

GENTILI, Pablo. Três teses sobre a relação trabalho e educação em tempos neoliberais. In: LOMBARDI, José Claudinei; SAVIANI, Dermeval; SANFELICE, José Luis (Org.). Capitalismo, trabalho e educação. Campinas, Autores Associados, 2002, p. 45-59.

GOMES, Nilma Lino. Diversidade e currículo. In: Indagações sobre currículo. Brasília: Ministério da Educação, Secretaria de Educação Básica, 2007.

GOMES, Nilma Lino (Org.) Apresentação: Desigualdades e diversidade na educação. Revista Educação e Sociedade. Campinas: vol. 33, n. 120, jul.- set. 2012, p. 687-693.

LUDKE, Menga; ANDRÉ, Marli E. D. A. Pesquisa em educação: abordagens qualitativas. 2 ed. Rio de Janeiro: E. P. U., 2017.

MACEDO, Elizabeth. Base Nacional Comum para currículos: direitos de aprendizagem e desenvolvimento para quem? Campinas: Educ. Soc., v. 36, no . 133, p. 891-908, out.-dez., 2015.

MINAYO, Maria Cecília de Souza. O desafio da pesquisa social. In: DESLANDES, Suely Ferreira. Pesquisa Social: teoria, método e criatividade. Petrópolis, RJ: Vozes, 2008, p. 9-29.

MOANTOAN, Maria Teresa Eglér. Inclusão escolar: o que é? Por quê? Como fazer? 1 ed. São Paulo: Moderna, 2003.

MOEHLECKE, Sabrina. As políticas de diversidade na educação no governo Lula. Cadernos de Pesquisa, v. 39, n. 137, maio/ago. 2009. Disponível em: http://www.scielo.br. Acesso em: 24 jul. 2017.

MOREIRA, Antônio Flávio; SILVA JÚNIOR, Paulo Melgaço da. Currículo, Transgressão e Diálogo: quando Outras Possibilidades se tornam necessárias. São Cristóvão, Sergipe, Brasil, Revista Tempos e Espaços em Educação, I, v. 9, n. 18, p. 45-54, jan./abr. 2016.

PATTO, M. H. S. A produção do fracasso escolar: histórias de submissão e rebeldia. São Paulo: T. A. Queiróz, 1990.

PIERUCCI, Antônio Flávio. Ciladas da diferença. 3. ed. São Paulo: Programa de Pós-Graduação em Sociologia da FFLCH - USP/Editora 34, 2013.

RODRIGUES, Tatiane Cosentino. A ascensão da diversidade nas políticas educacionais contemporâneas. São Carlos: UFSCar, 2011. 
RODRIGUEZ, Tatiane C.; ABRAMOWICZ, Anete. O debate contemporâneo sobre a diversidade e a diferença nas políticas e pesquisas em educação. Educação e Pesquisa. São Paulo, v. 39, n. 1, p. 15-30, jan./mar. 2013. Disponível em: http://www.scielo.br/pdf/ep/v39n1/v39n1a02.pdf. Acesso em: 11 set. 2016.

SALUSTIANO, Dorivaldo Alves; FIGUEIREDO, Rita Vieira de; FERNANDES. Anna Costa. Mediações da aprendizagem da língua escrita por alunos com deficiência mental. In: Atendimento Educacional Especializado: Deficiência Mental.

SEESP/SEED/MEC. Brasília/DF - 2007. Disponível em: http://portal.mec.gov.br/ seesp/arquivos/pdf/aee_dm.pdf. Acesso em: 31 ago. 2019.

SANTOS, Boaventura de Sousa. Para uma sociologia das ausências e uma sociologia das emergências. Revista Crítica de Ciências Sociais [online], 63, 2002. Disponível em: http://rccs.revues.org/1285; DOI: 10.4000/rccs.1285. Acesso em: 10 jul. 2018.

SAVIANI, Dermeval. História das ideias pedagógicas no Brasil. 4 ed. Campinas, SP: Autores Associados, 2013.

SILVA, Mara do Socorro. Tecendo saberes e práticas no aprender docente do campo: olhares, diálogos e interações do Pibid Diversidade. In.: Vozes do PIBID diversidade: epistemologias em diálogo. Interritórios: Revista de Educação. Universidade Federal de Pernambuco, Caruaru, Brasil. V. 4 n 7, 2018. Disponível em: https://periodicos.ufpe.br/revistas/interritorios/article/view/238244/30062. Acesso em: 26 jun. 2020.

SILVA. Tomás Tadeu da. $\mathbf{O}$ currículo como fetiche: a poética e a política do texto curricular. Belo Horizonte: autêntica, 2003.

SILVA. Tomás Tadeu da (Org.). Identidade e diferença: a perspectiva dos estudos culturais. 15 ed. Petrópolis: Vozes, 2014.

SOUSA, Mirtes Aparecida Almeida. A diversidade na escola: concepções e práticas docentes. Dissertação (Mestrado em Educação) - Centro de Humanidades. Universidade Federal de Campina Grande. Campina Grande 2018. 